\title{
Stroke recurrence in the different subtypes of ischemic stroke. The importance of the intracranial disease
}

\author{
Recorrência nos diferentes subtipos de acidente vascular cerebral isquêmico. \\ A importância da doença intracraniana. \\ Marcos C Lange1, Gustavo Ribas?', Valeria Scavasine1, Renata Dal-Prá Ducci', Danielle C. Mendes', Viviane \\ de Hiroki Flumignan Zétola ${ }^{1}$, Norberto Cabral'2, Tatjana Rundek ${ }^{3}$
}

\begin{abstract}
The aim of the study was to analyze the long-term recurrence rate in patients with a first-ever ischemic stroke secondary to intracranial large artery atherosclerosis (LAA) in a Brazilian population. Methods: All stroke patients admitted to the hospital between October 2012 and September 2015 were evaluated. The stroke mechanism subtypes were classified as cardioembolism, LAA, small-vessel occlusion, other determined etiologies, and stroke of undetermined etiology. Results: The 359 first-ever ischemic stroke patients were followed up for a mean time of $21.6 \pm 15.1$ months. The LAA intracranial (38.9\%) and extracranial (24.6\%) stroke patients presented with a higher stroke recurrence. Intracranial LAA [HR, 10.2 (3.6-29.1); $p<0.001]$ and extracranial LAA [HR, 5.05 (1.79-14.2); $p=0.002]$ were the only conditions to show positive correlation with the recurrence rate, after adjusting for risk factors, thrombolysis, and National Institutes of Health Stroke Scale score at admission. Conclusion: Intracranial LAA presents a higher incidence of recurrence of ischemic stroke when compared with other etiologies in a Southern Brazilian population.
\end{abstract}

Keywords: stroke; atherosclerosis; recurrence; risk factors.

\section{RESUMO}

O objetivo do presente estudo é analisar a taxa de recorrência a longo prazo em pacientes com o primeiro AVCi secundário à aterosclerose de grande artéria intracraniana em uma amostra brasileira. Métodos: Pacientes admitidos entre outubro de 2012 e setembro de 2015 foram analisados. Os subtipos do mecanismo de AVC foram classificados como cardioembolismo, aterosclerose de grandes artérias, oclusão de pequenos vasos, outras etiologias determinadas e AVCi de causa indeterminada. Resultados: Foram avaliados 359 pacientes com primeiro AVCi. O tempo médio de seguimento foi de 21,6 $\pm 15,1$ meses. A aterosclerose de grande artéria, intracraniana $(38,9 \%)$ e extracraniana (24,6\%), apresentou a maior taxa de recorrência. A aterosclerose de grande artéria intracraniana [HR, 10,2 (3,6-29,1); p < 0,001] e extracraniana [HR, 5,05 (1,79-14,2); p = 0,002] demonstraram correlação positiva com a taxa de recorrência, após o ajuste para fatores de risco, trombólise e gravidade dos sintomas na admissão. Conclusão: A aterosclerose de grande artéria, tanto intracraniana como extracraniana, apresenta maior recorrência comparado aos outros mecanismos de AVCi em uma amostra do Sul do Brasil.

Palavras-chave: Acidente vascular cerebral; aterosclerose; recidiva; fatores de risco.

Intracranial atherosclerosis is the mechanism of ischemic stroke in 6 a10\% of the patients in Western countries and $50 \%$ of patients in Eastern countries ${ }^{1,2,3,4,5}$. Patients with intracranial atherosclerosis exhibit an ischemic stroke recurrence rate of $14-19 \%$ within two years ${ }^{6,7}$. Until now, most of the current knowledge about intracranial atherosclerosis has come from the Northern Hemisphere. The aim of the present study was to analyze the long-term stroke recurrence rates among the Brazilian patient population with a first-ever ischemic stroke secondary to intracranial large artery atherosclerosis (LAA), compared to a first-ever ischemic stroke secondary to other mechanisms.

1Universidade Federal do Paraná, Hospital de Clínicas, Departamento de Neurologia, Curitiba PR, Brasil;

¿Universidade da Região de Joinville, Departamento de Medicina, Joinville SC, Brasil;

${ }^{3}$ University of Miami, Miller School of Medicine, Department of Neurology, Miami, FL, USA.

Correspondence: Marcos C. Lange; Departamento de Neurologia, HC /UFPR; Rua General Carneiro, 181 / $4^{\circ}$ andar; $80060-900$ Curitiba PR, Brasil; E-mail: langeneuro@gmail.com

Conflict of interest: There is no conflict of interest to declare.

Received 27 March 2018; Received in final form 29 May 2018; Accepted 26 June 2018. 


\section{METHODS}

This study was a retrospective analysis of prospective hospital data from all patients with a first-ever ischemic stroke, admitted to the Hospital de Clinicas of the Federal University of Paraná, between October 2012 and September 2015. The study was approved by the local ethics committee and the board waived the need for patient consent.

All patients had a brain scan [computed tomography (CT) or magnetic resonance (MR)] to confirm the presence of a lesion consistent with the clinical syndrome diagnosed during admission. The stroke mechanism subtypes were defined according to the SSS-TOAST classification system as cardioembolism (CE), LAA, small vessel occlusion (SVO), other determined etiologies (OTH), and stroke of undetermined etiology (UND); the mechanism was determined if there were evident or probable criteria ${ }^{8}$. To determine the stroke mechanism subtype, patients underwent electrocardiography, extracranial and intracranial Doppler ultrasound, transthoracic echocardiography, and at least one brain CT scan. In selected cases, transesophageal echocardiography, 24-hour Holter monitoring, CT angiography, MR angiography, or digital angiography were also performed.

Patients with LAA were further subclassified as patients with extracranial LAA, patients with intracranial LAA $(\geq 50 \%$ stenosis in any of the main arteries - carotid siphon, middle cerebral artery, anterior cerebral artery, posterior cerebral artery, vertebral artery and basilar artery) or patients with combined (extracranial plus intracranial) LAA, based on the topography of the symptomatic vessel. For the analyses, patients with combined LAA ( four patients) were included in the patients with extracranial LAA group. To substantiate the intracranial LAA, patients underwent at least two distinct noninvasive scans of contrast-enhanced MR angiography or CT angiography or transcranial Doppler ultrasound. If there was a contradiction in the results of the two scans, digital angiography was performed during hospital admission, to either confirm or exclude intracranial disease. All patients with intracranial LAA underwent a second noninvasive evaluation (MR angiography, CT angiography, or transcranial Doppler ultrasound) three months after the first set of scans to confirm the persistence of stenosis and the diagnosis of intracranial LAA. The intracranial stenosis was based on previously-published criteria ${ }^{9,10}$. All patients with intracranial LAA were treated medically.

The following risk factors were analyzed: age, sex, hypertension, diabetes mellitus, atrial fibrillation, hypercholesterolemia, and current smoking. Skin color was classified based on the Brazilian Institute of Geography and Statistics criteria $^{11}$. The in-hospital analyses included the National Institutes of Health Stroke Scale (NIHSS) scores, as well as systolic and diastolic blood pressure at admission. Patients were evaluated at outpatient visits, after discharge, to assess the follow-up modified Rankin Scale (mRS) score and risk of stroke recurrence. Stroke recurrence was defined as a focal neurological impairment of sudden onset lasting more than 24 hours and confirmed by a brain image during the follow-up period ${ }^{12}$. Patients discharged from the hospital were included in the present study if they were followed up for at least three months.

Analyses were performed using Stata/SE 14.1 software. Quantitative variables were described by mean and standard deviations, or median with minimum and maximum values. Categorical variables were presented as frequencies and percentages. For comparison of the etiological groups by quantitative variables, one-way analysis of variance (ANOVA) or the Kruskal-Wallis nonparametric test was used. Categorical variables were analyzed using a chi-square test. Normality of data was determined using the Kolmogorov-Smirnov test. Factors associated with recurrence were analyzed using univariate and multivariate Fine and Gray proportional hazards regression models (mortality as a competing risk) and the Wald test. For the multivariate model, all significant variables comparing different ischemic stroke mechanisms and those related to recurrence in the univariate analyses were considered. The subdistribution hazard ratio was estimated as the measure of association. Proportional hazard assumption was evaluated by cumulative incidence curves and analysis of the interaction between each variable and time. No evidence of violation of this condition was detected. Statistical significance was accepted for p-values $<0.05$.

\section{RESULTS}

Three hundred ninety-eight first-ever ischemic stroke patients were admitted to the hospital during the study period; 39 (9.8\%) were excluded for lack of follow-up in the first three months after discharge. Among the 359 patients evaluated, the mean age was $64.4 \pm 13.6$ years, 177 patients (49.3\%) were women, and 333 patients $(92.8 \%)$ had white skin color. The mean follow-up period was $21.6 \pm 15.1$ months. Brain CT was performed on all 359 patients; electrocardiography on 346 patients (96.4\%); extracranial and intracranial Doppler ultrasound on 315 patients (87.7\%); transthoracic echocardiography on 318 patients (88.6\%); transesophageal echocardiography on 69 patients (19.2\%); 24-hour Holter monitoring on 81 patients (22.6\%); CT angiography, MR angiography, or digital angiography on 184 patients (51.3\%); and brain MRI on 168 patients (46.8\%).

Eighteen patients (5\%) were classified as having intracranial LAA, 61 (17\%) as having extracranial LAA, 107 (29.8\%) as having CE, 90 (25.1\%) as having UND, 68 (18.9\%) as having SVO, and $15(4.2 \%)$ as having OTH stroke mechanism subtypes.

Hypertension was more common in patients with intracranial LAA (94.4\%) and SVO (95.6\%). Twelve patients (66.7\%) with intracranial LAA and 48 patients (70.6\%) with 
SVO had hyperlipidemia. Diabetes mellitus was observed more frequently in patients with extracranial LAA (39.3\%) and SVO (38.2\%), followed by intracranial LAA (33.3\%). The NIHSS score at admission was lower in intracranial LAA (2; $0-18)$, SVO (3.5; 0-13), and OTH ( $5 ; 0-20)$ when compared to the NIHSS scores of other ischemic stroke subtypes. Table 1 shows the demographic and admission data from different groups of patients. Antiplatelet therapy was introduced at the time of discharge for 15 patients (83.3\%) with intracranial LAA, 54 patients (93.1\%) with extracranial LAA, 67 patients (98.5\%) with SVO, 25 patients (26.3\%) with CE, 13 patients (86.7\%) with OTH, and 55 patients (88.7\%) with UND. Anticoagulation therapy was prescribed for 70 (73.8\%) patients with CE, three (16.7\%) with intracranial LAA, three (5.3\%) with extracranial LAA, two (13.3\%) with OTH, and four (6.6\%) with UND.

During the follow-up period, stroke recurrence was observed in 48 patients (13.4\%): seven patients (38.9\%) with intracranial LAA, 15 patients (24.6\%) with extracranial LAA, 12 patients $(11.2 \%)$ with CE, five patients $(7.3 \%)$ with SVO, and nine (10\%) UND patients. Patients classified under OTH did not present with stroke recurrence. Patients with intracranial LAA and extracranial LAA had higher stroke recurrence rates, as determined by univariate analyses (Table 2). When submitted to a multivariate analysis, the only variables correlated with stroke recurrence were intracranial and extracranial LAA stroke mechanisms (Table 3).

Functional independence ( $\mathrm{mRS}$ score $<3$ ) at the last review was observed in 13 patients (81.3\%) with intracranial LAA, 23 patients $(53.5 \%)$ with extracranial LAA, 50 patients $(67.6 \%)$ with CE, 48 patients $(82.8 \%)$ with SVO, nine patients $(64.3 \%)$ with OTH, and 32 patients $(61.5 \%)$ with UND $(\mathrm{p}=0.03)$.

\section{DISCUSSION}

The present study demonstrated that patients with intracranial and extracranial LAA presented with the highest stroke recurrence rate. Hypertension and hyperlipidemia were more common in intracranial LAA patients.

Previously-reported stroke recurrence rates for patients with intracranial LAA were $14 \%$ over two years and $23 \%$ over three years ${ }^{7,13}$. In our study, the stroke recurrence rate for patients with intracranial LAA was $38.9 \%$ over two years of follow-up. The stroke recurrence rates for other ischemic stroke subtypes in our study were very similar to previouslyreported rates in long-term studies ${ }^{14,15}$. The most likely reasons for the higher stroke recurrence observed in patients with intracranial LAA was the increased vulnerability caused by intracranial stenosis ${ }^{16}$. In addition, the patients in our study presented with a higher number of atherosclerotic risk factors, predominantly hypertension, hyperlipidemia, and diabetes mellitus when compared with the patients in another large case-control study ${ }^{17}$. A similar set of risk factors was observed in another recent study done in Southern Brazil $^{18}$. These findings could be explained by the patients having a more complex atherosclerotic disease, increasing the recurrence risk of ischemic stroke in this population.

In the current study, intracranial LAA patients showed less severe neurological deficits, as evaluated by the NIHSS at admission, with a good recovery, as demonstrated by the mRS. Previous studies have demonstrated that patients with low disability levels showed reduced compliance towards continuation of stroke prevention therapy ${ }^{19}$, thereby abrogating the long-term benefits of aggressive medical management, as

Table 1. Demographic data for first-ever ischemic stroke patients, classified by stroke mechanism.

\begin{tabular}{|c|c|c|c|c|c|c|c|}
\hline Variable & ILAA & ELAA & CE & SVO & ОTH & UND & $p$-value \\
\hline Population & 18 & 61 & 107 & 68 & 15 & 90 & \\
\hline Age (Mean \pm SD) & $63.3 \pm 16.5$ & $63.1 \pm 12.9$ & $64.8 \pm 12.6$ & $66.6 \pm 14.7$ & $58.5 \pm 14.9$ & $64.5 \pm 13.3$ & $0.371^{\star}$ \\
\hline Female sex (N [\%]) & $7(38.9)$ & $28(45.9)$ & 57 (53.3) & $37(54.4)$ & $9(60)$ & $39(43.3)$ & $0.491 * \star$ \\
\hline White skin color (N [\%]) & $16(88.9)$ & $58(95.1)$ & $100(94.3)$ & $63(92.6)$ & 14 (93.3) & 82 (91.1) & $0.892 * \star$ \\
\hline Hypertension (N [\%]) & $17(94.4)$ & $49(80.3)$ & $91(85.1)$ & 65 (95.6) & 8 (53.3) & $65(73)$ & $<0.001^{* *}$ \\
\hline Diabetes mellitus (N [\%]) & $6(33.3)$ & 24 (39.3) & $23(21.5)$ & $26(38.2)$ & $1(6.7)$ & $29(32.2)$ & $0.028 * *$ \\
\hline Hyperlipidemia (N [\%]) & $12(66.7)$ & $38(62.3)$ & $59(55.1)$ & $48(70.6)$ & $7(46.7)$ & $47(52.2)$ & $0.169 * \star$ \\
\hline Current smoker (N [\%]) & $5(27.8)$ & 24 (39.3) & $21(19.6)$ & $14(20.6)$ & $4(26.7)$ & $27(30)$ & $0.088 * *$ \\
\hline Atrial fibrillation (N [\%]) & $0(0)$ & $2(3.3)$ & $62(57.9)$ & $0(0)$ & $0(0)$ & $2(2.2)$ & $<0.001 * *$ \\
\hline Systolic blood pressure at admission (Mean \pm SD) & $153.4 \pm 23.5$ & $150.2 \pm 25.3$ & $150.1 \pm 34.3$ & $158.5 \pm 31.9$ & $133.7 \pm 19.1$ & $151.5 \pm 34.1$ & $0.149 *$ \\
\hline Diastolic blood pressure at admission (Mean \pm SD) & $86.1 \pm 12.1$ & $88.0 \pm 14.3$ & $89.8 \pm 20.6$ & $92.7 \pm 17.1$ & $77.6 \pm 9.8$ & $87.7 \pm 20.0$ & $0.089 *$ \\
\hline NIHSS at admission (Med (min-max]) & $2(0-18)$ & $10.5(0-24)$ & $10(0-26)$ & $3.5(0-13)$ & $5(0-20)$ & $11(0-29)$ & $<0.001 * \star \star$ \\
\hline Thrombolysis therapy (N [\%]) & $3(16.7)$ & $28(45.9)$ & $51(47.7)$ & $16(23.5)$ & $3(20)$ & $36(40)$ & $0.004 * \star$ \\
\hline Modified Rankin score $<3$ at last visit (N [\%]) & $13(81.3)$ & $23(53.5)$ & $50(67.6)$ & $48(82.8)$ & $9(64.3)$ & $32(61.5)$ & $0.030 * *$ \\
\hline
\end{tabular}
undetermined; ${ }^{*}$ ANOVA, ${ }^{* *}$ chi-squared test, ${ }^{* \star \star *}$ Kruskal-Wallis. 
Table 2. Univariate analyses for stroke recurrence for firstever ischemic stroke patients.

\begin{tabular}{lccc}
\hline Variable & p-value & SHR & $95 \% \mathrm{Cl}$ \\
\hline Age & 0.805 & 1.003 & $0.98-1.03$ \\
\hline Sex & 0.237 & 1.40 & $0.80-2.45$ \\
\hline Skin color & 0.665 & 0.73 & $0.17-3.04$ \\
\hline Hypertension & 0.135 & 2.04 & $0.80-5.21$ \\
\hline Diabetes mellitus & 0.679 & 0.88 & $0.48-1.61$ \\
\hline Hyperlipidemia & 0.747 & 1.10 & $0.62-1.95$ \\
\hline Current smoker & 0.464 & 0.76 & $0.37-1.57$ \\
\hline Atrial fibrillation & 0.819 & 0.92 & $0.43-1.94$ \\
Systolic blood pressure at admission & 0.501 & 1.003 & $0.99-1.01$ \\
\hline Diastolic blood pressure at admission & 0.213 & 1.01 & $0.99-1.03$ \\
\hline Thrombolysis & 0.763 & 0.92 & $0.53-1.60$ \\
\hline NIHSS at on admission & 0.924 & 1.002 & $0.96-1.05$ \\
\hline Stroke mechanism & & & \\
\hline ILAA & $<0.001$ & 9.64 & $3.35-27.7$ \\
\hline ELAA & 0.002 & 4.82 & $1.79-13.0$ \\
\hline CE & 0.313 & 1.68 & $0.61-4.61$ \\
\hline SVO (ref) & - & - & - \\
\hline Other* & & & \\
\hline UND & 0.358 & 1.64 & $0.57-4.72$ \\
\hline SHRsubditribution hazadratiofA & & & \\
\hline
\end{tabular}

SHR: subdistribution hazard ratio; ILAA: intracranial large artery atherosclerosis; ELAA: extracranial large artery atherosclerosis; CE: cardioembolism; SVO: small vessels occlusion; UND: undetermined; *Not analyzed.

reported in the Stenting and Aggressive Medical Management for Preventing Recurrent Stroke in Intracranial Stenosis trial ${ }^{20}$. Furthermore, the impact of the low disability in patients with intracranial LAA, as observed in the present study, did not reduce the recurrence, as recently reported in a subgroup analysis of the Clopidogrel in High-Risk Patients with Acute Nondisabling Cerebrovascular Events trial, where patients with intracranial artery stenosis and previous minor ischemic stroke, or moderate-to-high-risk transitory ischemic attack had a $12.5 \%$ chance of recurrence within 90 days, and patients without intracranial artery stenosis had a $5.4 \%$ chance of recurrence within the same period ${ }^{21}$.

The most important limitation of the present study was the fact that it was a retrospective analysis of data collected from a single hospital. However, we carried out extensive workups in the majority of patients, confirming the stroke mechanism with a high degree of accuracy. A second challenge was in the accurate identification of ethnicity, as much of the Brazilian population is multi-ethnic with a predominance of European ancestry but some proportion of African and Amerindian
Table 3. Multivariate model of stroke recurrence for first-ever ischemic stroke patients.

\begin{tabular}{lccc}
\hline Stroke mechanism* & $\mathrm{p}$-value & SHR & $95 \% \mathrm{Cl}$ \\
\hline ILAA & $<0.001$ & 10.3 & $3.56-29.6$ \\
ELAA & 0.001 & 5.38 & $1.95-14.8$ \\
CE & 0.521 & 1.50 & $0.44-5.15$ \\
SVO (reference) & - & - & - \\
UND & 0.249 & 2.05 & $0.61-6.93$ \\
\hline SHR: subdistribution & hazard & ratio, ILAA: & intracranial large artery \\
atherosclerosis; ELAA: extracranial large artery atherosclerosis; CE: & Cardioembolism; SVO: small vessels occlusion; UND: undetermined. Fine and \\
Gray proportional hazards regression models with mortality as competing \\
risk. *Adjusted for hypertension, diabetes mellitus, atrial fibrillation, \\
thrombolysis and NIHSS at admission.
\end{tabular}

ancestry as well ${ }^{22,23}$. The intracranial investigation was done by transcranial Doppler ultrasound in the majority of patients and this may have underestimated the frequency of this disease in the population. Beside this, a diagnosis of intracranial LAA was based on the stenosis without consideration of the vessel wall. Therefore, the initial study selection may have included patients with diagnoses other than atherosclerosis and excluded patients with advanced atherosclerosis in the absence of stenosis ${ }^{24}$. To reduce this bias, a confirmatory vascular image was taken three months later to identify and exclude potential unrelated mechanisms (evanescent stenosis, dissection, reversible cerebral vasoconstriction syndrome, and vasculitis). Some important markers for recurrence and outcome in intracranial LAA, as a collateral pattern and stroke mechanism, were not considered in the current study ${ }^{25,26}$. Despite these limitations, to the best of our knowledge, this study is the first to be performed in a low- to middle-income country in the Southern Hemisphere, to demonstrate the importance of diagnosing intracranial LAA, given the high rate of recurrent stroke.

In conclusion, the present study suggests that patients who have suffered a stroke due to intracranial and extracranial LAA present with a high frequency of other risk factors and are at high risk for stroke recurrence. Mitigation of risk factors could reduce the prevalence of stroke recurrence in patients with LAA.

\section{ACKNOWLEDGMENTS}

Marcia Olandoski (Pontifícia Universidade Católica do Paraná) for statistical analysis.

\section{References}

1. White H, Boden-Albala B, Wang C, Elkind MS, Rundek T, Wright CB et al. Ischemic stroke subtype incidence among whites, blacks, and Hispanics: the Northern Manhattan Study. Circulation. 2005 Mar;111(10):1327-31. https://doi.org/10.1161/01.CIR.0000157736.19739.D0

2. Arenillas JF, Molina CA, Chacón P, Rovira A, Montaner J, Coscojuela P et al. High lipoprotein (a), diabetes, and the extent of symptomatic intracranial atherosclerosis. Neurology. 2004 Jul;63(1):27-32. https://doi.org/10.1212/01.WNL.0000132637.30287.B4

3. Weimar C, Goertler M, Harms L, Diener HC. Distribution and outcome of symptomatic stenoses and occlusions in patients with acute cerebral ischemia. Arch Neurol. 2006 Sep;63(9):1287-91. https://doi.org/10.1001/archneur.63.9.1287 
4. Wong KS, Huang YN, Gao S, Lam WW, Chan YL, Kay R. Intracranial stenosis in Chinese patients with acute stroke. Neurology. 1998 Mar;50(3):812-3. https://doi.org/10.1212/WNL.50.3.812

5. De Silva DA, Woon FP, Lee MP, Chen CP, Chang HM, Wong MC. South Asian patients with ischemic stroke: intracranial large arteries are the predominant site of disease. Stroke. 2007 Sep;38(9):2592-4. https://doi.org/10.1161/STROKEAHA.107.484584

6. Kasner SE, Chimowitz MI, Lynn MJ, Howlett-Smith $\mathrm{H}$, Stern BJ, Hertzberg VS et al. Predictors of ischemic stroke in the territory of a symptomatic intracranial arterial stenosis. Circulation. 2006 Jan;113(4):555-63. https://doi.org/10.1161/CIRCULATIONAHA.105.578229

7. Mazighi M, Tanasescu R, Ducrocq X, Vicaut E, Bracard S, Houdart E et al. Prospective study of symptomatic atherothrombotic intracranial stenoses: the GESICA study. Neurology. 2006 Apr;66(8):1187-91. https://doi.org/10.1212/01.wnl.0000208404.94585.b2

8. Ay H, Furie KL, Singhal A, Smith WS, Sorensen AG, Koroshetz WJ. An evidence-based causative classification system for acute ischemic stroke. Ann Neurol. 2005 Nov;58(5):688-97. https://doi.org/10.1002/ana.20617

9. Feldmann E, Wilterdink JL, Kosinski A, Lynn M, Chimowitz MI, Sarafin $J$ et al. The stroke outcomes and neuroimaging of intracranial atherosclerosis (SONIA) trial. Neurology. 2007 Jun;68(24):2099-106. https://doi.org/10.1212/01.wnl.0000261488.05906.c1

10. Chimowitz MI, Lynn MJ, Howlett-Smith H, Stern BJ, Hertzberg VS, Frankel MR et al. Comparison of warfarin and aspirin for symptomatic intracranial arterial stenosis. N Engl J Med. 2005 Mar;352(13):1305-16. https://doi.org/10.1056/NEJMoa043033

11. Instituto Brasileiro de Geografia e Estatística - IBGE. Censo 2010. Rio de Janeiro: Instituto Brasileiro de Geografia e Estatística; 2013 [cited 2013 May 20]. Available from: https://www.censo2010.ibge.gov.br/apps/mapa/

12. World Health Organization - WHO. Section 1: Introduction, 1-4. 2006 [cited 2017 May]. Available from: http://www.who.int/chp/steps/ stroke/manual/en/

13. Weber R, Kraywinkel K, Diener HC, Weimar C. Symptomatic intracranial atherosclerotic stenoses: prevalence and prognosis in patients with acute cerebral ischemia. Cerebrovasc Dis. 2010;30(2):188-93. https://doi.org/10.1159/000317107

14. Petty GW, Brown RD Jr, Whisnant JP, Sicks JD, O’Fallon WM, Wiebers DO. Ischemic stroke subtypes : a population-based study of functional outcome, survival, and recurrence. Stroke. 2000 May;31(5):1062-8. https://doi.org/10.1161/01.STR.31.5.1062

15. Kolominsky-Rabas PL, Weber M, Gefeller O, Neundoerfer B, Heuschmann PU. Epidemiology of ischemic stroke subtypes according to TOAST criteria: incidence, recurrence, and long-term survival in ischemic stroke subtypes: a population-based study. Stroke. 2001 Dec;32(12):2735-40. https://doi.org/10.1161/hs1201.100209
16. Arenillas JF. Intracranial atherosclerosis: current concepts. Stroke. 2011 Jan;42(1 Suppl):S20-3. https://doi.org/10.1161/STROKEAHA.110.597278

17. O’Donnell MJ, Xavier D, Liu L, Zhang H, Chin SL, Rao-Melacini P et al. Risk factors for ischaemic and intracerebral haemorrhagic stroke in 22 countries (the INTERSTROKE study): a case-control study. Lancet. 2010 Jul;376(9735):112-23. https://doi.org/10.1016/S0140-6736(10)60834-3

18. Marrone LCP, Diogo LP, Oliveira FM, Trentin S, Scalco RS, Almeida AG et al. Risk factors among stroke subtypes in Brazil. J Stroke Cerebrovasc Dis. 2013 Jan;22(1):32-5. https://doi.org/10.1016/j.jstrokecerebrovasdis.2011.05.022

19. Bushnell CD, Zimmer LO, Pan W, Olson DM, Zhao X, Meteleva T et al. Persistence with stroke prevention medications 3 months after hospitalization. Arch Neurol. 2010 Dec;67(12):1456-63. https://doi.org/10.1001/archneurol.2010.190

20. Derdeyn CP, Chimowitz MI, Lynn MJ, Fiorella D, Turan TN, Janis LS et al. Aggressive medical treatment with or without stenting in high-risk patients with intracranial artery stenosis (SAMMPRIS): the final results of a randomised trial. Lancet. 2014 Jan;383(9914):333-41. https://doi.org/10.1016/S0140-6736(13)62038-3

21. Liu L, Wong KS, Leng X, Pu Y, Wang Y, Jing J et al. Dual antiplatelet therapy in stroke and ICAS: subgroup analysis of CHANCE. Neurology. 2015 Sep;85(13):1154-62. https://doi.org/10.1212/WNL.0000000000001972

22. Cardena MM, Ribeiro-Dos-Santos A, Santos S, Mansur AJ, Pereira AC, Fridman C. Assessment of the relationship between self-declared ethnicity, mitochondrial haplogroups and genomic ancestry in Brazilian individuals. PLoS One. 2013 Apr;8(4):e62005. https://doi.org/10.1371/journal.pone.0062005

23. Pena SD, Di Pietro G, Fuchshuber-Moraes M, Genro JP, Hutz $\mathrm{MH}$, Kehdy FS et al. The genomic ancestry of individuals from different geographical regions of Brazil is more uniform than expected. PLoS One. 2011 Feb;6(2):e17063. https://doi.org/10.1371/journal.pone.0017063

24. Gutierrez J, Elkind MS, Virmani R, Goldman J, Honig L, Morgello $S$ et al. A pathological perspective on the natural history of cerebral atherosclerosis. Int J Stroke. 2015 Oct;10(7):1074-80. https://doi.org/10.1111/ijs.12496

25. Lau AY, Wong EH, Wong A, Mok VC, Leung TW, Wong KS. Significance of good collateral compensation in symptomatic intracranial atherosclerosis. Cerebrovasc Dis. 2012;33(6):517-24 https://doi.org/10.1159/000337332

26. López-Cancio E, Mathus MG, Romano JG, Liebeskind DS, Prabhakaran S, Turan TN et al. Infarct patterns, collateral and likely causative mechanisms of stroke in symptomatic intracranial atherosclerosis. Cerebrovasc Dis 2014;37(6):417-22. https://doi.org/10.1159/000362922 